\title{
Epistemology without guidance
}

\author{
Nick Hughes 1
}

Accepted: 3 May 2021/Published online: 2 June 2021

(C) The Author(s) 2021

\begin{abstract}
Epistemologists often appeal to the idea that a normative theory must provide useful, usable, guidance to argue for one normative epistemology over another. I argue that this is a mistake. Guidance considerations have no role to play in theory choice in epistemology. I show how this has implications for debates about the possibility and scope of epistemic dilemmas, the legitimacy of idealisation in Bayesian epistemology, uniqueness versus permissivism, sharp versus mushy credences, and internalism versus externalism.
\end{abstract}

Keywords Action-guidance - Epistemic dilemmas · Norms of belief · Bayesian epistemology · Probabilism · Epistemic ought-implies-can · Imprecise credences · Non-ideal rationality $\cdot$ Uniqueness $\cdot$ Permissivism

\section{Introduction}

Many epistemologists think that reflecting on the connection between normativity and guidance can help us to decide between competing views about the most general, fundamental, epistemic norms of belief_-norms like: be rational; believe only truths; believe what your evidence supports, and; believe only what you know. ${ }^{1}$ The idea is that these norms must be capable of giving us adequate (useful, usable,

\footnotetext{
1 See, for instance, Pollock (1987), Ginet (1975), Goldman (1999), Wedgwood (2002, 2017), Langsam (2008), Gluer and Wikforss (2009, 2010, 2013), Greco (2012, fc), Gibbons (2013), Way (2016), Kiesewetter (2017), Lord (2018), Sullivan-Bissett (2018), Fox (2019), Fassio and Gao (fc), Rinard (2018), Barnett (ms), and Neta (ms), amongst many others.
}

Nick Hughes

nickhowellhughes@gmail.com

1 Faculty of Philosophy, University of Oxford, Oxford, UK 
etc.) guidance, and that we should accept one set of norms, or one way of understanding that set of norms, over another on the grounds that the former, unlike the latter, meets this demand.

In this article, I'll argue that it is much harder to use guidance considerations to decide between competing views about the fundamental norms of belief than it is often thought. ${ }^{2}$ My approach will be to look in detail at a test case-a normative epistemology which appears to do very badly when it comes to giving useful, usable, guidance. I'll argue that guidance considerations don't rule it out. From this, I'll argue, it follows that guidance considerations have a much smaller role (at best) to play in deciding between competing views about these norms than it is widely assumed. It also follows that they have little or no role to play in a number of other debates in epistemology, including debates about the legitimacy of idealisation in Bayesian epistemology; uniqueness versus permissivism; and sharp versus mushy credences.

As we will see, over the course of the discussion a pattern will emerge. Some conceptions of adequate guidance are more demanding than others. The demanding conceptions cannot help us to decide between competing views because they are too demanding-if we accept them then we will have to admit that no normative epistemology is adequately guiding. If we accept less demanding conceptions of guidance, on the other hand, then every (sane!) normative epistemology will turn out to be adequately guiding.

The plan is this. Section 2 presents a puzzle about epistemic normativity. Section 3 presents a possible solution to it-this will be our test case. Section 4 describes a natural way of thinking about what adequate guidance must be if this view fails to provide it. Section 5 argues that this conception of adequate guidance is too strong for it to help us decide between competing views about the fundamental norms. In short, the problem is that if this is what adequate guidance amounts to, then no normative epistemology gives it. Section 6 looks at one obvious way of weakening our understanding of what constitutes adequate guidance in order to overcome the problem. Section 7 argues that whilst this seems at first to do the

\footnotetext{
${ }^{2}$ On one way of interpreting 'fundamental', it is plausible that only 'believe only truths' and 'believe only what you know' have a claim to being fundamental norms of belief. After all, insofar as one ought to be rational, or believe what one's evidence supports, it is presumably because one ought to have true or knowledgeable beliefs. I mean to use 'fundamental' more broadly, to include all of these norms, which are very general in their scope, by comparison to local, contingent, norms like, say, 'Don't believe what they tell you on Fox News'. By 'competing views', one thing I have in mind is the ongoing debate between epistemologists with internalist leanings and epistemologists with externalist leanings. Many in the internalist camp think guidance considerations show that you ought-are epistemically required - to be rational. Put another way: a belief is justified iff it is rational...truth and knowledge be damned (see Pollock, Ginet, Lord and Kiesewetter, for instance). Many externalists, by contrast, think that truth and knowledge are what really matters, not rationality (e.g., Sutton, 2005, 2007; Littlejohn, 2013, fc; Williamson, 2013, fc). On this view, a belief is justified iff it is knowledgeable, rationality be damned. It is this debate which I am primarily interested in here. However, there is another debate in which guidance considerations have played a role, which asks: in what sense, if any, is truth a constitutive norm of belief. Here the truth norm and the rationality norm typically aren't taken to be competitors in the way internalists and externalists take them to be. Rather, the focus is on how belief and truth (and rationality) are related. I will also have some things to say about this debate, in Sect. 10.2. Thanks to an anonymous referee for pointing out the need for clarification here.
} 
trick, ultimately it still cannot help us to decide between competing views. Section 8 replies to some objections. Sections 9and 10 consider several other ways of thinking about guidance and argue that none of them does the job either. Section 11 discusses a variety of ways in which the point generalises to other debates about the norms of belief, including uniqueness versus permissivism; sharp versus mushy credences; conflicts between substantive and structural norms of rational belief; and the demands of Bayesian probabilistic coherence. Section 12 concludes.

\section{Conflicting norms: a puzzle}

On to the puzzle. It begins with two plausible-looking claims:

TRUTH: One ought (epistemically) to only believe truths.

RATIONALITY: One ought (epistemically) to be epistemically rational.

There's plenty of scope for debate about how TRUTH and RATIONALITY should be interpreted, but it is hard to deny that each is true in some sense. Now consider the following case:

BRUEGHEL: The Crucifixion, a painting by Pieter Brueghel the Younger, hangs in a church in a small town in Northern Italy. A gang of thieves intends to steal it. After weeks of planning, late one March night they quietly disable the church alarm system, break in through the apse door, snatch the painting from its frame, and make their escape. Back at the boss's house, they celebrate; they expect to negotiate a large ransom from the government for its return. Meanwhile, the local police are also celebrating. After being tipped off about the thieves' plan, they set up a hidden camera in the church and replaced the painting with an identical-looking replica. Now they can use the camera footage to identify the thieves. The actual Brueghel is sitting in a vault in the basement of the Uffizi.

Let 'p' = 'the thieves have a painting by Brueghel'. According to TRUTH the thieves ought not to believe that $\mathrm{p}$ as it is false. But wouldn't it be irrational for them not to believe it ${ }^{3}$ Herein lies the problem. If that's right, then there are cases in which TRUTH and RATIONALITY issue conflicting instructions. ${ }^{4}$ Sometimes TRUTH tells you not to believe that $\mathrm{p}$ even whilst RATIONALITY tells you to believe that $\mathrm{p}$. But it's logically impossible to both believe that $\mathrm{p}$ and not believe that $\mathrm{p}$ at the same time. Call any case in which TRUTH and RATIONALITY conflict a 'conflict case'. The puzzle is: what should we say about conflict cases?

\footnotetext{
${ }^{3}$ Epistemologists who think there are only negative epistemic duties (e.g. Littlejohn, 2013; Nelson, 2010) will deny this. In Hughes (2019a, fc1, ms) I argue that they are mistaken.

4 C.f. Hughes $(2017,2019 a, b)$.
} 


\section{Dilemmism}

My view-dilemmism-is that TRUTH and RATIONALITY both express requirements. You're required to believe that $\mathrm{p}$ in conflict cases, and at the same time required not to believe that p. ${ }^{5}$ And that's that. Neither requirement outweighs or takes priority over the other, and we cannot resolve the conflict by appealing to the idea that there are different senses of 'ought' at work or anything like that. Just as there are moral dilemmas, in which you fall short of living up to the demands of morality whatever you do, so too are there epistemic dilemmas. ${ }^{6}$

That's the dilemmic view in simple outline. Clearly, many details need to be filled in, and there's also the matter of why we should prefer it to the myriad possible alternatives. I won't discuss any of that here. The point of this article isn't to defend dilemmism. Its role here is only to serve as a test case for the idea that guidance considerations can help us decide between competing views about the fundamental norms of belief, and this outline will suffice for it to serve that role.

A natural thought is that dilemmism must be rejected because it fails to give adequate guidance. In conflict cases, it says that you must believe that $p$ and must not believe that $p$. This "guidance" looks completely useless. Furthermore, it's plausible that if almost any (sane) view about the fundamental norms of belief could be dismissed on the grounds that it fails to give adequate guidance, dilemmism could be. This makes it the perfect test case. If it can be shown that guidance considerations don't favour rejecting dilemmism then we can reasonably conclude that such considerations have at best a marginal role to play in theorising about the fundamental norms of belief.

\section{Motivating norms and perfect guides}

So far, we have the intuitive thought that dilemmism fails to give adequate guidance. Call this the 'guidance objection'. It needs to be sharpened up. What exactly is it about dilemmism that makes it inadequate as a guide?

\subsection{Ignorance and inability}

One obvious worry is that in conflict cases at least one of dilemmism's demands is opaque to you. Think about the BRUEGHel case. The thieves are not in a position to know that TRUTH requires them not to believe that $\mathrm{p}$. When a normative theory allows for the possibility of circumstances in which you are required to $\varphi$ but not in a position to know it, it fails, in some intuitive sense, to be available as a guide. This suggests a condition on adequate guidance that dilemmism fails to satisfy. Call it TRANSPARENCY:

\footnotetext{
5 At first glance this might look like a logical contradiction. It isn't. See Hughes (2019a, fc2).

6 See Hughes (2019a) for a defence of this view. This paper elaborates and expands on some things I said there.
} 
TRANSPARENCY: A normative theory is adequately guiding only if, whenever it requires you to $\varphi$, you are in a position to know that it requires you to $\varphi$.

Secondly, in conflict cases dilemmism gives you instructions it is manifestly impossible to follow. When a normative theory allows for the possibility that you can be required to $\varphi$ even though you are clearly unable to $\varphi$, it is again in some intuitive sense not usable as a guide. This gives us a second condition on adequate guidance that dilemmism fails to satisfy. Call it ABILITY:

ABILITY: A normative theory is adequately guiding only if, whenever it requires you to $\varphi$, you are able to $\varphi$.

\subsection{Motivating norms}

Is there a unified notion of guidance that connects these two seemingly disparate desiderata? There may be. Whatever else it takes for you to have been guided by a fact, that fact must surely have exerted some kind of influence on you. But not just any old kind of influence will do. The fact that he's drunk might influence John's behaviour by causing him to start a fight. But his decision to start the fight wasn't guided by the fact that he was drunk-it was a reason why he started the fight, but it wasn't his reason; his reason was the way the other guy looked at him. The contrast here is between explanatory reasons and motivating reasons: between facts that help to explain someone's action, and facts that motivated them to perform it. A natural thought is that a person's action has been guided by the fact that $\mathrm{p}$ if, and only if, they act as they do at least in part because - that is to say, for the reason that $-p$, where the 'because' is understood as that of a motivating reason. ${ }^{7}$ It follows that your action has been guided by a norm's requirement that you $\varphi$ if and only if you act as you do in part because the norm requires you to $\varphi$. This sounds quite plausible. Levitical law prohibits consumption of any animal that 'parts the hoof but does not chew the cud'. 8 If you order the salmon rather than the pork, then you comply with this law. But you may be unaware of the law, or simply indifferent to it. Unless you order the salmon rather than the pork in part because Levitical law requires that of you, it is natural to think, your decision hasn't been guided by the law. Your compliance is merely coincidental.

Call this idea MOTIVATING NORMs:

MOTIVATING NORMS: When a norm requires someone to $\varphi$, their behaviour is guided by the norm if and only if they act as they do at least in part because (i.e. for the reason that) the norm requires them to $\varphi$.

MOTIVATING NORMS isn't without problems, as we'll see later. But it's a good starting point, for as we'll see shortly it provides us with a way of thinking about guidance according to which dilemmism is clearly inadequate.

\footnotetext{
7 I say 'in part' because although we often talk of the reason why someone did something, in reality a complete explanation will almost always make reference to a plurality of reasons.

${ }^{8}$ I borrow this example from Smith (2012).
} 


\subsection{Perfect guides}

As it stands, motivating NORMs is schematic. How we flesh it out will depend on how we think about motivating reasons. So far, we have assumed 'factualism': the view that worldly facts can be our motivating reasons. ${ }^{9}$ Some philosophers think that it is not worldly facts that are our motivating reasons, but rather the contents of our beliefs-i.e. propositions. ${ }^{10}$ Another view-psychologism-maintains that they are our psychological states themselves. ${ }^{11}$ We need not concern ourselves with this debate yet. I'll assume a factualist interpretation of MOTIVATING NORMS for now. Later on, we'll look at non-factualist interpretations of it. In the meantime, following on from MOTIVATING NORMS, let's call 'PERFECT GUIDES' the idea that a normative theory is adequately guiding if and only if, whenever it requires you to $\varphi$, you are able to $\varphi$ for the reason that you are required to $\varphi$ :

PERFECT GUIDES: A normative theory is adequately guiding if and only if, whenever it requires you to $\varphi$, you are able to $\varphi$ for the reason that it requires you to $\varphi$.

Why 'PERFECT' GUIDES? Because the claim is that a normative theory is adequately guiding only if, whenever it requires you to $\varphi$, you can $\varphi$ for the reason that you are required to $\varphi$. We'll see soon why this is important. ${ }^{12}$

PERFECT GUIDES looks fairly plausible at first glance, and there are good reasons to think that it entails both TRANSPARENCY and ABILITY. A compelling case can be made for the claim that the fact that $\mathrm{p}$ can be one's reason for $\varphi$-ing only if one knows that p. Let's call this HYMAN's THESIS, since it's most closely associated with Hyman (1999, 2015):

HYMAN's THESIS: The fact that $\mathrm{p}$ can be one's reason for $\varphi$-ing only if one knows that $\mathrm{p}$.

Why accept HYMAN's THESIS? Here is a variation on the argument Hyman gives. Once, at a house party, I went to go into a bedroom. On opening the door, I saw a panther lying on the bed. I nearly jumped out of my skin and immediately slammed the door shut. After taking a few seconds to gather myself I realised that of course there couldn't really be a panther in the room. This was urban England, not rural Indonesia. It must be a life-sized stuffed toy. Why did I slam the door? It wasn't because there was a panther in the room, since there wasn't. No true explanation has

\footnotetext{
9 Factualists include Alverez (2010) and Hyman (2015).

${ }^{10}$ For example, Comesana and McGrath (2014). I'll assume here, since nothing turns on it, that a fact is a true proposition. 'Propositionalists' about motivating reasons think that false propositions can also be our motivating reasons.

11 E.g. Davidson (1963).

12 PERFECT GUIDES doesn't quite flow naturally from MOTIVATING NORMS. MOTIVATING NORMS says that your actions have been guided by a requirement to $\varphi$ iff you act as you do in part because you're required to $\varphi$. But it doesn't specify that the action in question must be $\varphi$-ing rather than something else. Some philosophers (Jay, 2012; Talbot, 2016) have inferred from this point that guidance considerations don't motivate ABILITY. I think they're right, but I won't press the matter here since my concerns with PERFECT GUIDES and ABILITY, to be presented shortly, are independent of this point.
} 
a false explanans. A better explanation is that it was because I believed there was a panther in the room. Now suppose instead (and here we depart from actual events) that in addition to the toy panther on the bed, unbeknownst to me there really was a panther in the room, hidden from view, lying under the bed. It should be obvious that this makes no explanatory difference. I still didn't slam the door because there was a panther in the room, but rather because I believed that there was. And yet my belief was both true and (let's imagine) rational. So why couldn't the fact that there was a panther in the room be the reason why I slammed the door? Hyman maintains (and I agree) that the most plausible answer is because I didn't know that there was a panther in the room. If that's right, what best explains it? Answer: HYMAN's THESIS. ${ }^{13}$

If HYMAN's THESIS is right, then PERFECT GUIDES entails TRANSPARENCY. And ABILITY is straightforward: you can't $\varphi$ for the reason that $p$ if you can't $\varphi$.

This adds some substance to the guidance objection; we now have more than just an intuition. Furthermore, it's clear that if PERFECT GUIDES is right, then dilemmism fails to give adequate guidance. So, do we have a good reason to reject dilemmism here?

\section{Imperfect guides}

We do not. PERFECT GUIDES is too strong. Neither of TRANSPARENCY or ABILITY are genuine conditions on adequate guidance.

\subsection{On TRANSPARENCY}

The problem with TRANSPARENCY it is that there are a variety of reasons, both theoretical and empirical, to think that no non-trivial condition is such that, whenever it obtains, one is in a position to know that it obtains (in other words, no non-trivial condition is, as Williamson (2000) has put it, 'luminous'). ${ }^{14}$ This applies to the condition being required to $\varphi$ as much as it does to any other. It follows that no possible normative epistemology satisfies TRANSPARENCY. This is a familiar observation. As Srinivasan (2015) points out, the sensible conclusion to draw from it isn't that no normative epistemology is capable of giving adequate guidance, but rather that TRANSPARENCY is too strong.

\subsection{On ABILITY}

What about ABILITY? A knock-on effect shows that it is also too strong. According to MOTIVATING NORMS you can only be guided in $\varphi$-ing by a requirement to $\varphi$ if you are both able to $\varphi$ and know that you're required to $\varphi$. Think back to the Levitical law example. If you order the salmon rather than the pork, then you are certainly able to comply with the law, since actuality implies possibility. But if you are unaware of

\footnotetext{
13 I argued against the thesis in Hughes (2014). I have since changed my mind.

${ }^{14}$ For a survey of these reasons, see Srinivasan (2015).
} 
the law, then you're not guided by it when you decide on the salmon. Again, your compliance is coincidental. Both of the ability and knowledge conditions must be met if you are to be guided by a requirement. If one is but the other isn't, then it's not as though you have somehow been partially guided by the requirement. You haven't been guided by it at all. Recall, the thought behind ABILITY is that requirements must be guiding yet aren't if you can't comply with them. But as we've already seen, the limits of our knowledge guarantee that requirements sometimes aren't guiding. In that case, there is simply no ground on which to maintain that you must always be able to comply with requirements lest they be incapable of guiding you. It's too late, that ship has sailed. The upshot is that ABILITY is left unmotivated. ${ }^{15}$

Ability comes in grades. $\varphi$-ing may be logically possible, but not metaphysically possible; metaphysically possible, but not nomologically possible...and so on. Dilemmism is committed to the claim that one can be required to do that which is logically impossible - the strongest grade of impossibility. One might think that the argument only shows that some interpretations of ABILITY cannot be motivated by guidance considerations, but that would be a mistake. On the MOTIVATING NORMS schema, luminosity failure precludes guidance considerations from motivating even the least committal interpretation of ABILITY, according to which the kind of ability in question is that of bare logical possibility. If, due to ignorance, you cannot always be guided by the requirements that bind you, there is simply no guidance-related motivation even for saying that it must always be logically possible to satisfy those requirements.

\section{Degrees of guidance}

If we interpret the claim that a normative epistemology must be adequately guiding along the lines of PERFECT GUIDES no normative epistemology gives adequate guidance. So it is no objection to dilemmism that it comes up short. A different approach is needed if we are to make sense of the guidance objection. There are two ways we can go at this point. We can try to weaken PERFECT GUIDES, or we can start looking at alternatives to MOTIVATING NORMS or the factualist interpretation of it. We'll get to the second idea later. Before we do, I want to explore the first.

PERFECT GUIDES says that a normative theory is adequately guiding only if, whenever it requires you to $\varphi$, you are able to $\varphi$ for the reason that you are required to $\varphi$. So if there are any cases in which you are required to $\varphi$ but cannot $\varphi$ for that reason, the theory is inadequate. But the idea of adequate guidance need not be so stringent and simpleminded. We might instead view the relationship between theories and guidance as a matter of degrees. The thought would be that even if no normative theory is perfectly guiding-even if we can't always be guided by its imperatives - the more often a theory can be used as a guide - the more frequently we can be guided by its imperatives-the better. The idea isn't that the more

\footnotetext{
15 See Hughes (2018a) for a more detailed version of this argument.
} 
demands it makes, the better a normative theory is. Totalitarianism isn't a theoretical virtue. Rather, it is that the more often one is in a position to be guided by the demands it does make, the better. Ceteris paribus, one normative theory is superior to another if we are more often in a position to be guided by the instructions issued by the former than we are the latter.

However, as I will now argue, dilemmism doesn't do worse than the alternatives when it comes to giving guidance. I realise that this may sound implausible, but hear me out.

\section{Ubiquitous irrationality}

Firstly, it is important to appreciate that dilemmism isn't only a view about conflict cases. Most of the time TRUTH and RATIONALiTy don't conflict with one another. When they concord, dilemmism says that you are required to comply with each. Such cases present no special difficulties when it comes to guidance.

Secondly, guidance failures will be commonplace for any view that accepts TRUTH - the knowledge norm of belief, for instance. Of course, such views will usually not make logically impossible demands, but that is beside the point. Recall, if MOTIVATING NORMS is right, then in order to be guided by a norm on a particular occasion, one needs both to know what it requires of one and to be able to do what it requires. The fact that a non-dilemmic theory like the knowledge norm doesn't have the additional property of demanding the impossible is irrelevant. Non-dilemmic TRUTH-centric theories don't do any better than dilemmism when it comes to degrees-of-guidance.

The more interesting question is theories that reject TRUTH but accept RATIONALITY, which those who press the guidance objection will presumably prefer. In a recent paper, Cohen and Comesana (fc) consider a dilemmic view similar in some respects to mine. In response to it, they write that “...even if there are [epistemic dilemmas] it is implausible that they are as pervasive as this position would have it. [If this view is right] we collectively face epistemic dilemmas multiple times an hour" (fc: 13). This will likely resonate with those sympathetic to the guidance objection. Maybe we can tolerate dilemmas, and along with them guidance failures, if they are recherché anomalies - freak events in our epistemic lives. But if dilemmism is right, then they are utterly commonplace. In that case, the thought goes, the problem with dilemmism isn't that if it's right the norms of belief aren't always available as guides, it's that they are unavailable far too often.

Popular opinion seems to be that RATIONALITY-centric views do much better here. Even if we are not always in a position to know what it requires of us, surely we're in a much better position with respect to RATIONALITY than we are with respect to TRUTH? Cohen and Comesana seem to think so. In a telling passage, they describe the idea that everyone is irrational multiple times a day as 'extremely radical' (fc: 3).

Popular opinion is understandable. Cases in which $p$ is false but one is not in a position to know it are easy to imagine. Cases in which it is irrational for one to believe that $p$, but one is not in a position to know it are harder to imagine. 
Nevertheless, there are good reasons to think that popular opinion is mistaken. The impression that RATIONALITY-centric views do better when it comes to degrees of guidance depends, I will argue, on easily overlooked but false tacit assumptions about the nature and richness of our cognitive lives and about the scope of the fundamental norms of belief. I will take these assumptions in turn.

Firstly, Cohen and Comesana are unduly optimistic about our rationality. Over the last 50-years psychologists have uncovered a variety of biases in reasoning and doxastic attitude formation, retention, and revision, to which we are prone. For instance, we exhibit confirmation bias: a tendency to seek and accept at face value evidence that supports our beliefs whilst avoiding disconfirming evidence ${ }^{16}$; we exhibit hindsight bias: when we know the outcome of an event, we judge it to be more probable on the evidence available before the outcome than we do when we are ignorant of the outcome ${ }^{17}$; and we exhibit implicit bias: our judgements are unconsciously influenced by prejudices and stereotypes. ${ }^{18}$ When a belief is formed, retained, or revised under the influence of these biases it is, intuitively, not rational (at least, when the influence of the bias is sufficiently strong). ${ }^{19}$ And these are only three biases amongst many. The picture emerging from cognitive psychology is one in which epistemic irrationality is a pervasive feature of human cognition.

Does it follow that guidance failures will be commonplace even for theories that reject TRUTH but accept RATIONALITY? Not straightforwardly. For suppose that most of the time when you irrationally form, retain, or revise a belief as a result of the influence of bias you are in a position to know that you are being irrational; you only need to turn your attention towards the matter and correct yourself. In that case, the fact that you are habitually irrational poses no threat to the idea that RATIONALITY is good at guiding you, or at least better than the alternatives.

But is there any reason to think that a bias-infected belief reveals its pathology to your introspective gaze? If the answer is 'no', then you' re not in a position to know that RATIONALITY requires you not to hold the belief, at least not without further information and investigation. But it is highly doubtful that the answer is 'yes' - at least, not usually. A wealth of studies indicate that biases usually operate at a subpersonal level, with the result that they simply cannot be detected by introspection. ${ }^{20}$ As Wilson and Brekke (1994) put it: bad judgements, unlike bad food, don't smell.

This suggests that guidance failures will be commonplace even for RATIONALITYcentric views. But will they be as commonplace as they are for dilemmism? Reflection on the richness of our cognitive lives suggests that they will.

According to our best theories of belief, for you to believe that $\mathrm{p}$ is for the proposition that $\mathrm{p}$ to play a certain role in your cognitive life. Very roughly, for it to

\footnotetext{
16 Lord (1979) et al.

17 Roese and Vohs (2012) et al.

18 Brownstein (2019) et al.

19 See Hughes (fc3) for an argument to back up the intuition and for an explanation of why such beliefs are irrational, which draws on recent work by Lasonen-Aarnio $(2010$, fc) on knowledge-conducive dispositions.

${ }^{20}$ See Wilson (2002) for an overview.
} 
be a proposition that you are disposed to take as a given in your reasoning and decision-making, amongst other things. So understood you have billions of beliefs, even on a very conservative estimate. ${ }^{21}$ Moreover, they are in a state of constant flux. Every second you spend walking down the street, thousands of them spin and shuffle. Of course, you will never consciously entertain any more than a tiny fraction of them. Nevertheless, they are there in the background, constantly shifting as your experience of the world unfolds. ${ }^{22,23}$

Epistemologists sometimes overlook this fact. It is striking that Cohen and Comesana worry about the possibility that we face epistemic dilemmas 'multiple' times an hour. That's an enormous understatement; if there are epistemic dilemmas, they are far, far more common than that. The important point for our purposes is that what goes for dilemmism here also goes for RATIONALITY. When we combine the fact that irrationality-caused-by-bias is an ordinary feature of human cognition with the fact that we are massively prolific in our doxastic attitude formation, there is every reason to think that guidance failures are utterly pervasive even for RATIONALITYcentric views. But if so, then RATIONALITY-centric views do no better than the alternatives when it comes to giving guidance. ${ }^{24}$

Proponents of RATIONALITY-centric views might respond by conceding that guidance failures are commonplace for RATIONALITY-centric views but maintain that they are not as commonplace as they are for dilemmism and that this is a reason to prefer the former theories to the latter. I want to say two things in response. Firstly, even if the frequency of guidance failures is greater for the dilemmist than it is for the RATIONALITY-centric theorist, we must ask whether this is a difference that makes a difference. We must also ask how this measurement will be made. At the very

\footnotetext{
21 This assumes that beliefs are countable, which is questionable. See Treanor (2013) for discussion. I will work with the assumption here, but nothing depends on it. Even if belief is better understood as having, say, a map-like structure, no theory of belief could reasonably deny that the map is extremely rich in detail. More generally, no theory of belief could reasonably deny that our cognitive lives exhibit the kind of richness that my argument assumes them to.

22 The notion of belief in play here is dispositional rather than occurrent. Some philosophers draw a distinction between dispositional beliefs and dispositions to believe-Audi (1994), for instance. But even if one accepts that distinction, and even if one thinks that we have rather few dispositional beliefs (as opposed to dispositions to believe), this won't make a difference for the argument. Dispositions can be rational or irrational, so everything I say here could be rephrased in terms of a rationality norm for dispositions to believe.

23 The fact that most of our beliefs are produced automatically might suggest that MOTIVATING NORMS is a bad model for guidance. The worry is that most of the time we simply do not form or revise beliefs for the reason that TRUTH or RATIONALITY requires us to. There may be something to this idea, but we should be careful-perhaps merely being counterfactually sensitive to a norm is sufficient for one to count as having been guided by it on the MOTIVATING NORMS schema. In addition, we might think that TRUTH and RATIONALITY merely need to be available as guides for when we reflectively scrutinise beliefs we have already formed. In any case, in Sect. $10.1 \mathrm{I}$ will consider a way of thinking about guidance that takes this concern into account.

24 The problem is not that some instances of irrationality will inevitably slip through the net, since it is impossible for us to monitor the entire corpus of our beliefs at once. Rather, it is that even when turn our attention to individual beliefs for inspection, we are often unable to identify those that are irrational, since our biases are not usually introspectively accessible. Thanks to Jonathan Way for pointing out the need for clarification here.
} 
least, there surely needs to be not just a difference but a significant difference in the frequency of occasions on which the norms of belief are, or are not, available as guides according to competing theories for us to have a reason to prefer one theory over another. But whatever the difference in frequencies turns out to be, it is doubtful whether it is enough to justify adopting a RATIONALITY-centric theory over dilemmism. At the end of the day, once we appreciate how prolific we are in doxastic attitude formation, it becomes apparent that guidance failures will be ubiquitous come what may-it is no less normal for RATIONALITY-centric theories to fail to be available as guides than it is for TRUTH-centric theories and dilemmism. It is this fact, I suggest, rather than hard-to-establish relative frequencies, that should guide us in theory choice.

Secondly, although they are useful (they make things vivid), strictly speaking we don't need the empirical results from psychology to make the point here. Once we appreciate why this is, we can see that the idea that RATIONALITY-centric views are more often available as guides in any significant sense is incredibly hard to sustain.

Why don't we need the empirical results? Because we should expect the fundamental norms of belief, whatever they are, to exhibit a very high level of generality. They should apply to all agents in all possible situations. This is something all parties in the debate should agree on. It is difficult to see how exotic modally remote worlds populated by envatted agents, evil epistemic demons, Boltzmann brains, philosophical zombies, infallible oracles, and the like could tell us anything about the fundamental norms were they only intended to apply locally, in the actual world. These worlds, being modally remote, would simply be irrelevant to the question of what we should believe. Yet, epistemologists who theorise about the fundamental norms do not treat them as irrelevant; they go to great lengths to accommodate them, and with good reason. Some norms-'don't believe what they tell you on Fox News', 'trust your doctor' - are local, applying only given contingent features of the actual world. They don't hold in worlds in which Fox News is known to be reliable and doctors are known to be unreliable. But norms like 'believe only truths' and 'be rational' surely aren't like that. The fact that these norms are pitched at a very high level of generality means that we can run the argument using merely possible biased agents.

With this in mind, consider Blixa. I will stipulate two facts about him. The first is that he is highly prone to all manner of cognitive biases. The second is that he has no introspective access to the influence of these biases. When he reflects on his biased beliefs, they look just fine to him, and not because he isn't looking hard enough.

In all probability, Blixa is an actual person. But even if not, he is a possible person. Nothing I have stipulated about him is incompatible with what we know about the human mind. That our judgements can be influenced by introspectively inaccessible sub-personal processes is as well-established as any thesis in psychology. Moreover, the fundamental norms of belief apply to Blixa as much as they do to us. There may be a limit on how poorly a mind can function whilst the person in possession of it remains an agent, and so one to whom the fundamental 
norms of belief apply, but it is hard to see why anyone would think that Blixa is beyond the pale. He isn't a mere animal, he's just an idiot. ${ }^{25}$

How will Blixa fare when it comes to being guided by the RATIONALITY norm? Not at all well. Occasions on which Blixa is unable to be guided by the norm because he's not in a position to know what it requires of him will be very common indeed. Blixa isn't in any better a position with respect to RATIONALITY than he is with respect to TRUTH when it comes to guidance. And remember: Blixa is only one possible person. We can imagine infinitely many others just like him.

Can fans of guidance considerations legitimately ignore or discount Blixa and his kin when comparing dilemmism, TRUTH-centric, and RATIONALITY-centric theories on degreesof-guidance-giving? Given the level of generality that these norms are supposed to apply at, it is hard to see how they can. But if they can't, then it should be clear that the prospects of vindicating a RATIONALITY-centric theory by appealing to degrees-of-guidance-giving are utterly hopeless. Once we recognise that we must take into account, not just more-orless-normal agents in the actual world, but also a vast number of possible agents in a vast plurality of possible worlds, the claim that RATIONALITY is significantly more frequently available as a guide than TRUTH or dilemmism looks like a total non-starter. It becomes hard to even make sense of the idea that RATIONALITY-centric views could be more frequently available as a guide than their rivals. One struggles to see how such a measurement could be made in the first place, even in principle. ${ }^{26}$

\section{Interlude: three concerns addressed}

Before we continue, I want to address three potential concerns one might have about the argument so far. If you're already on board, you can skip straight to Sect. 9.

\subsection{Blame-and-control epistemology}

First, in light of the above, those who feel the pull of the intuition that RATIONALITY simply must be guiding (to a certain degree) might argue that biased beliefs are in fact rational. However, at this point it is reasonable to ask: if rationality does not even require one not to be biased, what does it require? And why should we think that it is an interesting normative notion at all? As I see it, it is a desideratum on a theory of epistemic rationality that it delivers the result that the kinds of biased beliefs under discussion are irrational. If a theory doesn't do so, so much the worse

\footnotetext{
25 It might be claimed that although the RATIONALITY norm still applies to Blixa, it makes different demands of him than it does of us. I see no reason to think this is true unless one accepts a view ('blameand-control epistemology') which I will argue against shortly.

26 Of course, we will also take into account worlds populated by super-rational agents with no biases. But this only makes it look harder to make the relevant measurement, not easier.
} 
for the theory. ${ }^{27}$ Unlike with the false beliefs of an envatted agent, which are the product of a well-functioning mind placed in an uncooperative environment-and hence rational, even though false - there isn't anything epistemically positive to say about bias-infected beliefs. As such, it is hard not to suspect that those who still maintain at this point that we must not yet have found the right theory of rationality are driven by a picture of rationality according to which an irrational belief is necessarily a belief that one can be appropriately blamed for holding. Since biasinfected beliefs are the product of introspectively inaccessible sub-personal processes over which we have little control, it is natural to think that we are, in some sense, not to blame for them. This impression is liable to strengthen when we realise that everyone harbours them and will continue to do so no matter how hard they try.

However, there are reasons to be dissatisfied with a blame-and-control epistemology. Here I will mention two. Firstly, consider monothematic delusions. People with Capgras delusion believe that a loved-one has been replaced by an identical-looking imposter and produce elaborate confabulations to explain away evidence to the contrary. They are not to blame for their beliefs, yet it is perfectly clear that they are profoundly irrational. There is more to rationality than mere blamelessness. If so, there is no motivation for rejecting the idea that unconscious biases can affect the rationality of belief on the grounds that we are blameless for harbouring the beliefs that result from them. Secondly, the conditions under which it is appropriate to blame a person for their behaviour, including their epistemic behaviour, are a motley bunch, and are highly sensitive to facts about the person's individual circumstances. This includes both their general circumstances (their upbringing, education, and intelligence, for instance) and their immediate circumstances (are they stressed, anxious, tired, distracted, etc.?). ${ }^{28}$ Any normative epistemology that tries to take account of all such considerations in order to deliver the result that one can never blamelessly violate a genuine a epistemic norm will almost certainly find it impossible to say anything very general about epistemic normativity. For this reason, a blame-and-control epistemology should be especially unappealing to those who endorse the MOTIVATING NORMS conception of guidance and think that it is important that our normative epistemology is available as a useful, usable, guide. The resulting epistemology, being hyper-sensitive to circumstantial fluctuations, will either have no principles at all, or principles so complex that no normal human being could possibly apply them. Either way, the result for a MOTIVATING NORMS conception of guidance will be the same: no guidance.

\footnotetext{
27 Internalists sometimes give theoretical significance to how things seem or appear to agents (e.g. Huemer, 2001; Smithies, 2019). They risk facing what I have elsewhere called the 'problem of laundered biases' (Hughes fc3). Does it seem or appear that $\mathrm{p}$ to an agent whose belief that $\mathrm{p}$ has a biased etiology? If the answer is 'yes', then insofar as these internalists take seemings and appearances to be evidence, they will have to say that seemings and appearances produced by biases are nonetheless good evidence. This is not an attractive thing to have to say (c.f. Siegel, 2017). But if the answer is 'no', then given the ubiquity of bias-infected beliefs, seemings and appearances must not be things we have particularly good epistemic access to. This would make them ill-suited to play the role that internalists want them to play.

28 Austin (1957) and Littlejohn (fc) make a similar point about excusing conditions.
} 


\subsection{Overgeneralisation?}

The second concern is about a potential overgeneralisation. It has seemed plausible to many philosophers that moral and prudential normative theories must be actionguiding. Do my arguments so far carry over to show that they aren't? If they do, one might think that this is more radical a conclusion than is the conclusion that normative epistemologies need not be guiding. The worry is that it is too radical. ${ }^{29}$

In reply, I would like to say several things. Firstly, we are currently considering a demanding conception of what it takes for a theory to be a useful guide. Later I will consider less demanding interpretations of the idea. I'll argue that they don't cause problems for dilemmism, not because we are in a bad state with regards to them no matter what normative epistemology we adopt, but rather because they are compatible with dilemmism counting as giving useful guidance even in conflict cases. One might think that morality and prudence must be action-guiding, but be untroubled by my arguments so far, because one has a liberal conception of guidance. I have no objection to this. ${ }^{30}$ So there is only a potential problem here if we think that the norms of morality and prudence must be guiding in the demanding ways I have discussed so far (for instance, that they must satisfy TRANSPARENCY and ABILITY).

Now, insofar as one does accept a demanding conception of guidance, it may well be that my arguments carry over to challenge the idea that morality and prudence must be guiding. ${ }^{31}$ One reason to think so is the fact that, whilst moral and prudential norms dictate how we should act rather than what we should believe, how we act depends on what we believe. So anyone who violates epistemic norms on belief-formation is in jeopardy of violating moral and prudential norms as a result. If so, the possibility that no moral or prudential theory can satisfy stringent demands on guidance-giving is something we may simply have to learn to live with, radical though it may be. ${ }^{32}$

\footnotetext{
29 Thanks to an anonymous referee for encouraging me to think about this.

30 Though I doubt that liberal conceptions of guidance will help us choose between competing moral and prudential theories, just as (I will argue) they cannot help us to choose between competing normative epistemologies.

31 Elsewhere (Hughes, 2018a, b) I have argued that guidance considerations cannot be used to motivate the claim that the moral 'ought' implies 'can'.

${ }^{32}$ However, it would be a mistake to suppose that this is a more radical conclusion than is the conclusion that normative epistemologies cannot satisfy stringent demands on guidance-giving. Why might one suppose that it is more radical? The best reason I can think of is idea that conforming with moral and prudential norms is somehow more important than is conforming with epistemic norms. It is easy to see the appeal of this idea. It's natural to think that if you fail to conform with epistemic norms, the worst that will happen is that you'll end up with bad beliefs. By contrast, if you fail to conform with moral and prudential norms, you risk doing harm to yourself and others, which seems worse. Hence, the reasoning goes, it's more important to conform to moral and prudential norms than it is to conform with epistemic norms, and so more important that they give use useful guidance. However, this reasoning is flawed. It ignores the connection between belief and action just mentioned; how we act depends on what we believe. If a person who violates epistemic norms is ipso facto in jeopardy of violating moral and prudential norms as a result, then adhering to epistemic norms is a precondition on reliably adhering to
} 
That said, we shouldn't be too quick to draw this conclusion. There may be a difference between moral and prudential norms, on the one hand, and epistemic norms, on the other, when it comes to guidance. As I have emphasised, part of the problem when it comes to epistemic norms has to do with how enormously prolific we are in doxastic attitude formation. By contrast, the number of (non-doxastic) morally and prudentially significant actions we are able to perform is comparatively small. Thousands of my beliefs can change in an instant. But I can't perform thousands of actions in an instant. This observation might be used to argue that guidance failures are less commonplace for moral and prudential norms than they are for epistemic norms, and that this difference means that we can use guidance considerations to choose between competing moral and prudential theories, even if we can't use them to choose between competing epistemologies. Now, I'm skeptical about the prospects this argument, but I can't rule it out here. Doing so would require a lengthy detour into competing theories of morality and prudence, which would take us too far afield. It remains a possibility, then.

\subsection{Specific ability versus general ability}

Some philosophers (Mele, 2002; Way \& Whiting, 2016) draw a distinction between having a specific ability to $\varphi$ and having a general ability to $\varphi$. Roughly, one has the specific ability to $\varphi$ only if one can $\varphi$ in present circumstances, whereas one can have a general ability to $\varphi$ even if one doesn't have the ability to $\varphi$ in present circumstances. For example, basketball superstar LeBron James has the ability to dunk on a regulation NBA hoop. This is true even when he is on an airplane with no ball, no hoop, and no room to jump. When he is on an airplane, he lacks the specific ability to dunk, but retains the general ability. When he is on the court, he has both the specific and the general ability.

The argument so far shows that we often lack the specific ability to be guided by norms like TRUTH and RATIONALITY, owing to ignorance, luminosity failure, and bias. But this does not show that we lack the general ability to be guided by them. Why is that? Well, when you know what TRUTH and RATIONALITY require of you, they are useful guides. By contrast, one might think that dilemmism isn't a useful guide even when you know what it demands of you, since it gives you impossible-to-follow instructions in conflict cases. Doesn't this show that guidance considerations can be used to rule it after all? ${ }^{33}$

It does not. First, we should note that, as I said earlier, dilemmism isn't only a view about conflict cases. Most of the time TRUTH and RATIONALITY don't conflict. When they concord, you have the general ability to be guided by dilemmism's demands just as much as you have the general ability to be guided by non-dilemmic epistemologies that endorse one of TRUTH or RATIONALITY. But, what about cases

Footnote 32 continued

moral and prudential norms. As such, it is hard to see how it could be more important to do the latter than it is to do the former.

33 Thanks to an anonymous referee for raising this objection and encouraging me to think about it. 
where you know what TRUTH and RATIONALITY require of you and they do conflict, giving rise to impossible-to-follow instructions? Aren't these cases a problem? No. The reason is simple: such case can never arise in the first place. When you know what both of TRUTH and RATIONALITY require of you, they do not issue conflicting demands. After all, if you know that p is true, you can't also know that it would be irrational for you not to believe that $\mathrm{p}$. (And likewise, if you know that $\mathrm{p}$ is false, you can't also know that you're rationally required to believe that $\mathrm{p}$ ). So, appealing to the distinction between specific and general abilities doesn't give us a guidancerelated argument against dilemmism.

\section{Guidance without factualism}

If we conceptualise guidance along the lines of a factualist reading of MOTIVATING NORMS, dilemmism does no worse at giving it than the alternatives. But there are a number of different ways of fleshing out MOTIVATING NORMs. Perhaps one of the alternatives tells against the view? In this section we'll look at the options. I'll argue that however we think about guidance within the MOTIVATING NORMS framework, dilemmism will still do no worse than its rivals at giving it.

\subsection{Propositionalism}

On the factualist interpretation, MOTIVATING NORMS is a demanding conception of guidance. One obvious worry has to do with how it interprets the claim that your action has been guided by a norm's requirement that you $\varphi$ only if you act for the reason that the norm requires you to $\varphi$. On the factualist interpretation, this entails that you are required to $\varphi$ by the norm (there are no false facts). But it is not obvious that you need to respond to the actual requirements that a norm generates in order to count as having been guided by it. Take one of the thieves. In the BRUEGHEL case TRUTH requires him not to believe that the painting in their possession is a Brueghel. But that's not how it looks from his point of view. He (presumably) believes that TRUTH permits him to believe that $p$. And had he not believed this, he wouldn't have believed that $p$. Isn't this enough for us to say that he has been guided by the TRUTH norm?

This is an idea that proponents of propositionalism about motivating reasons could take up. They could say that when one forms a doxastic attitude because one believes that it is required or permitted by a norm, one's reason for forming it is that the attitude is required by TRUTH. We can also add, if we like, that the belief in question must be rational. Since, unlike factualists, propositionalists think that false propositions can be one's motivating reasons, the fact that TRUTH actually requires the thief not to believe that $\mathrm{p}$ need not stand in the way of his having been guided by it.

Notice, however, that regardless of how we fill in the details, the notion of guidance in play here is not one that can be used to argue against dilemmism. If this is what adequate guidance is, a person who believes that $p$ in a conflict case may well have been guided by both TRUTH and RATIONALITY, even though they conflict with one another. After all, our thief may well believe-rationally believe-that RATIONALITY 
requires him to believe that they have a Brueghel and that TRUTH permits this belief. Dilemmism would turn out to be guiding in conflict cases after all.

\subsection{Propositionalism plus truth}

The problem with this way of thinking about guidance, when it comes to raising an objection to dilemmism, is that it denies that one must actually be required to $\varphi$ by a norm to have been guided by that norm. What, then, about the idea that one has been guided by a norm in $\varphi$-ing if one believes that it requires one to $\varphi$ and that belief is true, even if it is not knowledge? Again, we could add that the belief must also be rational.

This might look more attractive to those who press the guidance objection. We can't maintain that dilemmism gives useful guidance in conflict cases once a truth requirement is attached to the theory of guidance. The thief might rationally believe that RATIONALITY requires him to believe that $p$ and that TRUTH permits it, but he's wrong-TRUTH requires him not to believe that p. So according to this way of thinking about guidance, he hasn't been guided by TRUTH. He might instead believe, correctly, that he is required to believe that $\mathrm{p}$ and also required not to believe that $p$, but now ABILITY kicks in: it is manifestly impossible for him to do both of these things, and so it's hard to see what he's supposed to do with that information when it comes to deliberating about what to believe.

Crucially, if we employ this notion of guidance appeals to the ubiquity of human ignorance and irrationality will not show that none of the alternatives does any better than dilemmism at giving guidance. Take a RATIONALITY-centric view. Even if you're not in a position to know that RATIONALITY requires you to $\varphi$, it doesn't follow that you're not in a position to truly believe that it requires you to $\varphi$. And, unlike with the dilemmic view, your true beliefs about what a RATIONALITY-centric view requires you to do can serve as a helpful basis for deliberation about what to believe-whether, for example, to believe that $p$ or not believe that $p$. This is because, in virtue of the fact that RATIONALITY-centric views disavow the possibility of dilemmas, your true beliefs about what a RATIONALITY-centric view requires you to do are guaranteed to point in a single direction: towards belief, suspension, or disbelief.

This looks like a problem for the dilemmist. Ultimately, however, it's hard to make sense of the idea that having a non-knowledgeable true belief about what it requires is sufficient for guidance by a norm but having a false belief about what it requires is not. According to this view, it is not facts about what a norm itself actually requires that guide us-HYMAN's THESIS tells us this. Rather, it is propositions - the contents of our representations of norms and requirements. But insofar as it is plausible that the contents of these representations guide us, they do so irrespective of whether they correspond to reality. So if we accept that a true belief is sufficient for guidance, we must also accept that a false belief is. It would be ad hoc to insist otherwise. But if a false belief is sufficient for guidance, then, as we have already seen, dilemmism turns out to be guiding after all, since a person in a conflict case may well believe that both TRUTH and RATIONALITY speak in favour of believing that $p$. The upshot is that there is no coherent notion of guidance to be found here on which dilemmism fails to be guidance-giving. 


\subsection{Psychologism}

Factualists and propositionalists agree on one thing: that it is not our psychological states themselves that are our motivating reasons. Proponents of psychologism disagree. They maintain that when one $\varphi$ 's, one's motivating reasons for $\varphi$-ing are, and could only ever be, one's psychological states-usually one's beliefs, desires and intentions. Does psychologism offer us a useful way of thinking about guidance?

The answer, it seems to me, is that proponents of psychologism will have a hard time making sense of guidance within the MOTIVATING NORMS schema in the first place. The reason is simple: norms and requirements are not psychological states of agents. My belief that UK law requires me to drive on the left is a psychological state, but the legal requirement, by which I am bound, is not. Given this, proponents of psychologism will have to say that a requirement to $\varphi$ generated by a norm (say, a requirement to believe that $\mathrm{p}$, because it would be irrational not to) is not, and can never be, amongst the reasons for which you $\varphi$. You can never $\varphi$ even in part because $\varphi$-ing is required by a norm. But in that case, it is rather hard to see how you could ever be guided by a norm or the requirements that it generates at all. Those who go in for the MOTIVATING NORMS schema are best advised to steer well clear of psychologism.

\section{Guidance without MOTIVATING NORMS}

In summary, if MOTIVATING NORMS is our model of normative guidance, then however we fill in the details dilemmism doesn't do any better or worse than the alternatives when it comes to giving it. But maybe the MOTIVATING NORMS framework doesn't capture the notion of guidance that those who press the guidance objection against dilemmism have in mind? Maybe there is a better way of thinking about guidance that really does show dilemmism to be a fatally flawed theory? Let's look at some of the options.

\subsection{Guiding dispositions}

A worry one might have about MOTIVATING NORMS is that it overintellectualises the concept of guidance. You probably hardly ever think to yourself 'it would be irrational for me not to believe that $p$, so I should believe that $p$ ' prior to forming a belief. Nevertheless, provided that the belief-formation process is appropriately sensitive to a norm and the demands that it makes, it seems natural to say that you are guided by that norm. ${ }^{34}$

\footnotetext{
34 As I said earlier, I am not entirely convinced that MOTIVATING NORMS overintellectualises in this way. But I won't press the issue here.
} 
One way to avoid this problem is to conceptualise guidance in terms of dispositions. Think about our thief again. He manifests a disposition to comply with TRUTH when he believes that the painting in their possession is a Brueghel-in normal circumstances he would only believe that they have a Brueghel if they actually do. His error can be explained by the fact that he is in abnormal circumstances. Given this, even though he doesn't believe in accordance with TRUTH, isn't it right to say that he has been guided by it when he believes what he does?

This looks promising as a way of thinking about guidance, and it doesn't require us to have formed higher-order beliefs in order to count as having been guided. But notice that, as with the non-factive propositionalist interpretation of MOTIVATING NORMS, regardless of how we fill in the details, the notion of guidance in play here is not one that can be used to argue against dilemmism. The reason is the same. If this is what adequate guidance is, a person who believes that $p$ in a conflict case may well have been guided by both TRUTH and RATIONALITY, even though they conflict with one another. ${ }^{35}$ The proposal is, roughly, that a person's action has been guided by a norm when it is the manifestation of a disposition to comply with the norm. Since the thief manifests a disposition to believe only truths, and to be rational, when he believes that they have a Brueghel, he has been guided by both norms according to this notion of guidance. But in that case, dilemmism is guidance-giving in conflict cases after all. ${ }^{36,37}$

There is, of course, a variation on this view according to which one has been guided by a norm just in case one successfully manifests a disposition to comply with it. However, there is no good argument from this view to the claim that we should reject dilemmism, because if we adopt it guidance failures will be commonplace for any view. The situation will be the same as with the factualist interpretation of MOTIVATING NORMS.

\footnotetext{
35 This way of thinking about guidance doesn't motivate an ABILITY condition, since it does not say that one must do what one is actually required to do in order to count as having been guided.

36 On the dispositionalist view, one might think that being rational just is a matter of being guided in the right way by TRUTH. I'm sympathetic (though I would replace TRUTH with the knowledge norm). But this doesn't look like a reason to reject RATIONALITY.

37 In a nuanced article on normative guidance, Railton (2006) points that most of our norm-guided behaviour does not involve conscious, explicit, representation of the norms by which we are guided. Norms are usually, as he puts it, internalized. One way in which this can happen is when one manifests a disposition to comply with the relevant norm without consciously representing it. But it is not the only way-Railton describes several other possibilities. For instance, a norm can also guide by unconsciously framing the options one considers in decision-making. Railton is a liberal and a pluralist about guidance. Liberal, in the sense that he doesn't insist on a demanding interpretation of the conditions under which one counts as having been guided by a norm (unlike, say, those who would go in for TRANSPARENCY or ABILITY). Pluralist, in the sense that he thinks there are multiple distinct ways in which one might be properly described as having been guided by a norm. I am sympathetic to much of what he says. However, there is no objection to dilemmism to be extracted from his observations-precisely because they are liberal and pluralistic. Everything he argues about guidance is compatible with dilemmism being guiding, even in conflict cases. (Thanks to an anonymous referee for encouraging me to think about Railton's views).
} 


\subsection{Constitutive and procedural norms}

It has seemed plausible to some philosophers that TRUTH is a constitutive norm of belief..$^{38}$ That is, what makes a mental state a belief, rather than something else, is that it is governed by тRUTH. Gluer and Wikforss () have argued against this idea on the grounds that TRUTH does not give useful guidance. Since dilemmism is committed to TRUTH, their argument, if it works, will torpedo dilemmism. ${ }^{39}$

Gluer and Wikforss's reasoning is different from the guidance-related arguments against TRUTH we've looked at so far. They reason that in order to be guided by TRUTH with respect to some proposition $p$, one must first form a belief as to whether the antecedent in the conditional 'One ought: if $p$ is false, not believe that $p$ ' is true. For until one has formed a belief about the antecedent, one cannot apply the norm. But to form a belief about whether the antecedent is true just is to form a belief about whether $p$ is true or false. Since what belief to form about the truth or falsity of $p$ is precisely the question that TRUTH was supposed to give one guidance on in the first place, Gluer and Wikforss reason, TRUTH does not give useful guidance. And if it doesn't give useful guidance, they argue, it is not a genuine norm of belief at all.

This is not a convincing argument. As Asbjorn Steglich-Petersen (2013) has pointed out, it relies on a narrow and demanding conception of guidance, according to which one counts as having been guided by a norm only if one forms a belief about what it requires of one. But as we are beginning to see, it is quite unclear why we should be so restrictive in our understanding of guidance. ${ }^{40}$ Consider, for instance, the dispositionalist conception of guidance just discussed. It does not require one to form a belief about what TRUTH requires of one in order for TRUTH to have given guidance-it is enough that one manifests a truth-conducive disposition. Yet it certainly looks like a way of having been guided by TRUTH. Or consider the distinction, which is sometimes made, between 'direct' and 'indirect' guidance. Even if one cannot be directly guided by TRUTH, it does not follow that one cannot be indirectly guided by it. ${ }^{41}$ How? By following 'procedural' norms. As a candidate, consider, for instance, an evidentialist spin on RATIONALITY, according to which one ought to believe that $\mathrm{p}$ only if one's evidence indicates that $p$ is true. The fact that this norm requires that one believes that $p$ only if one's evidence indicates that it is true (rather than, say, pleasant to believe) shows that TRUTH is playing a guiding role when one attempts to conform with the evidentialist norm, albeit indirectly. ${ }^{42}$

\footnotetext{
${ }^{38}$ E.g. Boghossian (2003) and Engel (2013).

${ }^{39}$ I take no stand on whether TRUTH is a constitutive norm of belief. But if Gluer and Wikforss's argument works it causes problems for TRUTH whether one takes it to be a constitutive or non-constitutive norm.

${ }^{40}$ It is also unclear why we should assume, as Gluer and Wikforss do, that if a would-be norm $N$ doesn't give useful guidance, it isn't a genuine norm. They provide no argument for this assumption, but given what we've seen so far one would be forgiven for questioning it. Until we get an argument, Gluer and Wikforss will have provided us with no reason to reject TRUTH.

${ }^{41}$ Steglich-Petersen (2013), Boghossian (2003, 2008), Engel (2013) and Wedgwood (2002, 2017).

${ }^{42}$ C.f. Steglich-Petersen (2013).
} 
Gluer and Wikforss's objection to TRUTH fails, then. ${ }^{43}$ Ipso facto, it fails to undermine dilemmism. However, there may be another objection in the vicinity. One might argue that since we cannot be directly guided by TRUTH, it cannot be a full-blooded requirement. Rather, it is at most merely an ideal (aim, goal, etc.) The only real requirement, one might think, is RATIONALITY. ${ }^{44}$

This reasoning should be rejected. It assumes that if $\varphi$-ing is an or ideal, aim, or goal, it isn't also a requirement. But counterexamples to that assumption are easy to find. The ideal for a building contractor is (let us suppose) to finish the job on time and on budget. This ideal cannot be 'directly' pursued, if by that we mean that one does not need a (fallible) means to achieve the end. Yet for all that it may well be that the contractor is also required to finish the job on time and on budget. I see no guidance-related reason for thinking that the situation is any different with TRUTH.

\subsection{Guiding ideals}

A more pressing concern for dilemmic views is that, in virtue of making logically impossible demands, they cannot even serve as guiding ideals or aims. Greco (2012) and Rinard (2018) deny the existence of epistemic dilemmas on these grounds. They argue like this. Let 'epistemic flawlessness' be the state of satisfying all of the epistemic requirements that bind one. Now consider:

1. Epistemic flawlessness is an ideal which can guide our doxastic attitude formation by being something we can strive towards.

2. If epistemic flawlessness is sometimes logically impossible, then it is not an ideal which can guide our doxastic attitude formation by being something we can strive towards.

3. Therefore, epistemic flawlessness is never logically impossible.

4. If there are epistemic dilemmas, then epistemic flawlessness is sometimes logically impossible.

5. Therefore, there are no epistemic dilemmas.

The crucial thought is that whilst satisfying certain demands might be beyond our reach, due to physical, psychological, epistemic, or computational limitations, they can nevertheless guide our behaviour by serving as ideals. But when they are logically or metaphysically impossible to satisfy, they cannot guide us in this way. Greco gives an example. You cannot match Eliud Kipchoge's record Marathon time. But you can nevertheless treat it as an ideal to strive towards, and, if you do, it can guide your training. But what could you do to get on your way to running faster than yourself? Similarly, what could you do that would be a step in the direction of both believing that $\mathrm{p}$ and not believing that $\mathrm{p}$ ? Nothing you could do would ever get you any closer to reaching these 'ideals'. So they are not ideals. And if they are not ideals, then they are not requirements either. Or so the argument goes.

\footnotetext{
43 Gluer and Wikforss reply to some of the points just discussed in their (2013) paper. I am not persuaded by their arguments, but there is no space to pursue the dialectic further here.

${ }^{44}$ Blanshard (1974) and Feldman (2000). Something like this line of thought also seems to be at work in Engel (2013) and Wedgwood (2002, 2017).
} 
This argument is also unpersuasive. Premise (1) is ambiguous. Once it is disambiguated, we can see that premise (2) is false on one reading and that the argument overgenerates on the other. Either way, it is not sound.

Unpacked, (1) says that 'satisfying all of the epistemic requirements that bind one is an ideal which can guide one's doxastic attitude formation by being something one can strive towards'. The 'all' here is ambiguous between a collective reading and a distributive reading. On the collective reading, the idea is that we take the epistemic requirements as a whole, and the ideal of epistemic flawlessness is to satisfy all of them. One will inevitably fall short, of course, but one can strive to do better by satisfying more of them. On the distributive reading we don't bundle up the requirements. Rather, we keep them separate, and for each requirement the ideal is that you satisfy it. On this reading, there are many ideals, not one. For each requirement, there is an ideal: satisfying that requirement.

Let's look at the collective reading of the argument first. On it, premise (2) is false. Even if it is logically impossible to satisfy all of the epistemic requirements that bind you, because some of them conflict with one another, it is possible to get closer to satisfying all of them. You will certainly fall short, but you can strive to do better and get closer by satisfying more of them. Let me explain.

The dilemmic view says that you should believe only truths and that you should be rational. Most of the time these requirements are jointly satisfiable. Just because there are cases in which, through sheer bad luck, you find yourself in a situation in which the demands of TRUTH and RATIONALITY conflict with one another, that doesn't mean you're always in that position. Now, in those cases in which they conflict, it is not logically possible to do what is required of you. So, if you ever find yourself in a dilemma situation, you will not achieve epistemic flawlessness. But you get closer to it the more of the requirements you do satisfy. In that case, epistemic flawlessness is an ideal that can guide your practice of doxastic attitude formation by being something you aspire to. Hence, premise (2) of the argument is false. Moreover, you can strive to avoid such conflict cases altogether by being judicious in your choice of epistemic sources. You'll almost certainly fail to live up to the ideal on some occasions, but that doesn't show that it is not an ideal towards which you can strive, and by which you can be guided.

On the collective reading of the argument, then, it is simply not true to say that a normative epistemology which allows for dilemmas does not provide us with a guiding ideal toward which we can strive. That leaves us with the distributive reading of the argument. Here the thought is that there cannot be conflicting requirements because, in virtue of it being logically impossible to satisfy each of them, you cannot even begin to get closer to doing what is required of you. On this reading, the argument might be thought to cause a problem for dilemmism, since there really is nothing you can do to get closer to satisfying the requirement 'believe that $\mathrm{p}$ and don't believe that $\mathrm{p}$ '.

However, read this way the argument overgenerates. Suppose that you're either required to $\varphi$ or required to not- $\varphi$ but have no way of knowing which and no chance of finding out. Can you use the ideal 'do what you're required to do' as a guide when making your decision about whether to $\varphi$ or not- $\varphi$ in this context? No. The most you can do is guess and hope you get it right. The requirement (whatever it 
happens to be) cannot be used by you as a guide to make your decision in any way whatsoever; you might as well flip a coin. But we already know from antiluminosity considerations that this situation-one where you are either required to $\varphi$ or required to not- $\varphi$ but have no way of knowing which-is possible. ${ }^{45}$ What's the difference between this situation and a conflict case? It's logically and metaphysically possible for you to do what's required of you, of course-that's a difference. But it isn't a relevant difference. What's important is that in this situation you cannot use the requirement that binds you as a guide to help you make you decision. As we might put it: an invisible ideal is not one that you can strive to satisfy. You might satisfy it by accident, of course-a case of fortuitous luck. But it can't play the role of guiding your behaviour. The upshot is that we should reject the argument on its distributive reading. However we interpret it, then, the flawlessness argument does not undermine dilemmism.

\subsection{Guiding reasons}

We still don't have a good guidance objection to dilemmism. Perhaps the problem is that we have focused on guidance by norms and the requirements on doxastic attitude formation that they generate. A different approach maintains that what should guide us is not doxastic requirements themselves, but rather the things that make it the case that we are required to adopt doxastic attitudes. The most popular way of developing this idea is within a factualist 'reasons-first' ideology. ${ }^{46}$ It is this approach that I will focus on here. According to this view, what you ought to do is determined by the balance of your reasons, and for a fact to be a reason for you to $\varphi$ it must be able to guide you. Specifically, you must be able to $\varphi$ for the reasons that make it the case that you ought to $\varphi$ :

REASONS-DETERMINE-OUGHTS: What you ought to do is determined by the balance of your reasons.

REASONS GUIDE: You are able to $\varphi$ for the reasons that make it the case that you ought to $\varphi$.

The conjunction of REASONS-DETERMINE-OUGHTS and REASONS GUIDE appears to motivate accepting RATIONALITY and rejecting TRUTH and (a fortiori) dilemmism. Why? Well, suppose for reductio that TRUTH is a genuine norm. If so, then given REASONS-DETERMINE-OUGHTS the fact that $\mathrm{p}$ is false is a reason for you not to believe

\footnotetext{
45 Jonathan Way has suggested to me that anti-luminosity considerations only show that you can be required to $\varphi$ or not required to $\varphi$ and have no way of knowing which. I disagree. Imagine a game in which you are required to move your piece one place forward if it is past 4 p.m. and required to not move your piece one place forward if it is not past 4 p.m. Now suppose that you have no way of checking the time. You are required to $\varphi$ or required to not- $\varphi$ and you have no way of knowing which. Bernhard Salow has raised a different objection. The claim that you might as well flip a coin suggests that it can be equally probable on your evidence that you are required to $\varphi$ as it is that you are required to not $\varphi$. One might think that anti-luminosity considerations don't get us this strong a result. I disagree. Analogues to Williamson's (2014) unmarked clock case can be constructed to demonstrate the possibility.

46 See, for instance, Kiesewetter (2017) and Lord (2015, 2018).
} 
that $\mathrm{p}$ even when you don't know that $\mathrm{p}$ is false. But this contravenes REASONS GUIDE. This is because, given HYMAN's THESIS, REASONS GUIDE entails:

FILTER: The fact that $\mathrm{p}$ is a reason for you to $\varphi$ only if you know that $\mathrm{p}$.

Since you cannot refrain from believing that $\mathrm{p}$ for the reason that $p$ is false when you're not in a position to know that $\mathrm{p}$ is false, we must reject TRUTH, and hence dilemmism. Instead, we should accept RATIONALITY-being rational, the thought goes, is just a matter of correctly responding to your reasons.

Here's the interesting thing. The reasoning here appears to be invulnerable to the arguments I have given so far, which trade on the observation that we often have poor epistemic access to facts about what's required of us. This is because FILTER isn't a luminosity principle. The claim isn't (1), it's (2):

1. $\mathrm{P}$ is a reason for you to $\varphi$ only if you know that $\mathrm{p}$ is a reason for you to $\varphi$.

2. $\mathrm{P}$ is a reason for you to $\varphi$ only if you know that $\mathrm{p}$.

(1) is a luminosity principle, but (2) isn't. The fact by which you are guided is that $p$, not that $p$ is a reason to $\varphi$. As a result, it is unaffected by anti-luminosity arguments. This approach bypasses worries about our poor epistemic access to the facts about what we should do by putting an epistemic filter in place according to which only the facts that we have access to make a difference to what we should do in the first place.

But why think that for $\mathrm{p}$ to be a reason of you to $\varphi$, you must be able to $\varphi$ for the reason that $\mathrm{p}$ ? The answer given by fans of REASONS GUIDE is that unless we accept it, we will not be able to rule out cases in which the only way you can do what you ought to do is by acting irrationally and getting lucky. Call this idea NO FLUKES:

NO FLUKES: It is always possible to do what you ought to do without having to act irrationally and getting lucky.

Think again about our thief. According to TRUTH he ought not to believe that they have a painting by Brueghel. But the only way he can conform with TRUTH is by brazenly and irrationally disregarding his evidence. This, the thought goes, is unacceptable. So, we should accept NO FLUKES, and NO FLUKES motivates REASONS GUIDE. $^{47}$

Does this shift of focus to guidance-by-reasons help us to decide between the fundamental norms? I don't think it does. The problem is that even if we accept FILTER and REASONS-DETERMINE-OUGHTS there will still be cases in which you can only do what you ought to by acting irrationally and getting lucky. NO FLUKES is false. But in that case, we have no motivation for REASONS GUIDE, and so no motivation for FILTER. And without FILTER, we have no argument for rejecting TRUTH and dilemmism.

\footnotetext{
47 It is sometimes boldly claimed that REASONS GUIDE is a conceptual truth (this is how I read Kiesewetter 2017), but this claim keeps bad company. Philosophers have frequently said the same thing about requirements, and we've already seen that that isn't true.
} 
To see why there will still be cases in which one ought to $\varphi$ yet cannot $\varphi$ without acting irrationally and getting lucky even if we accept FILTER and REASONSDETERMINE-OUGHTS, consider the following two cases:

RED TABLE: Grace is in room one. She sees a red table in front of her in normal lighting conditions and forms the belief that there is a red table in room one.

WHITE TABLE: Bella is in room two. She sees what appears to be a red table in front of her but is in fact a white table made to look red by a hidden light source. She forms the belief that there is a red table in room two.

Both beliefs are surely rational. Are they the beliefs Grace and Bella ought to have according to fans of the reasons-first approach? Given that they accept RATIONALITY and reject TRUTH one would expect the answer to be 'yes'. But in fact it seems to be 'no': Grace should believe that there is a red table in room one, but Bella should not believe that there is a red table in room two. Why? Remember that according to the view we are considering, what one ought to believe is determined by the balance of one's reasons (REASONS-DETERMINE-OUGHTS), and only known facts are reasons (FILTER). Grace knows that there is a red table in front of her and knows that she is in room one. So she has excellent reasons to believe that there's a red table in room one. Bella isn't so fortunate. She knows that she's in room two, but she doesn't know that there's a red table in front of her, since there isn't - the table is white. So it doesn't look like she has good reasons to believe that there is a red table in room two. And since what she should believe is determined by her reasons, it looks like she shouldn't believe that there is a table in room two.

Now, ask yourself: is it possible for Bella to do what she ought to without being irrational and getting lucky? Pretty clearly not. She'd be completely irrational to suspend on or disbelieve the proposition that there is a red table in room two. But in that case whITE TABLE is a counterexample to NO FLUKES. And since REASONS GUIDE depends on NO FLUKES, we have no reason to accept REASONS GUIDE.

Proponents of REASONS GUIDE are aware of this problem. In response, they point out that it appears to Bella that the table is red, and that this is something that she presumably knows (or at least, is in a position to know). ${ }^{48}$ They then argue that this fact - the fact that it appears to Bella that there is a red table in front of her-is a reason for her to believe that there is a red table in room two. Moreover, this reason carries substantial weight. Enough to make it the case that on the balance of reasons she ought to believe that there is a red table in room two. So in fact Bella ought to believe what it would be rational for her to believe. Moreover, she need not act irrationally and hope to get lucky in order to believe what she ought to. So, wHITE TABLE isn't a counterexample to NO FLUKES after all.

However, this reply doesn't work. In order for it to work, the fact that it appears to one that $p$ must always be as weighty a reason for one to believe that $p$ as is the fact that $p$. For if it is not, then it will be possible to construct good-case/bad-case pairs analogous to RED TABLE \& WHITE TABLE in which the subject in the bad case has less reason to believe that $\mathrm{p}$ than does the subject in the good case. In some of these

48 See, again, Kiesewetter (2017) and Lord (2018). 
cases, this difference in the weight of reasons will be enough to make it the case that the subject in the bad case ought not to believe that $p$, whilst the subject in the good case ought to believe that $p$. In these bad cases, the subject will be in the same position as Bella: the only way to do what she ought to do will be to act irrationally and get lucky. These cases would be counterexamples to NO FLUKES.

The problem is that there is no reason to think that the fact that it appears that $p$ is always as weighty a reason for one to believe that $p$ as is the fact that $p .{ }^{49}$ LasonenAarnio (2019) makes the point especially clearly. If one knows that $p$ and one knows that $p$ entails $\mathrm{q}$, then one has as strong a reason as there could be to believe that q: a reason that entails that q. By contrast, Lasonen-Aarnio notes, if one knows that $\mathrm{p}$ and one knows merely that $\mathrm{p}$ appears to entail $\mathrm{q}$, then one does not have as strong a reason as there could be to believe that $\mathrm{q}$ (i.e. an entailing reason) unless one can rule out the possibility that the appearance is misleading. Since appearances can be misleading, one cannot always rule out the possibility that an appearance that $p$ is misleading. Thus, there are possible cases in which the fact that it appears that $p$ is not as weighty a reason for one to believe that $\mathrm{p}$ as is the fact that $\mathrm{p}$ - WHITE TABLE is just such a case. ${ }^{50}$

So, NO FLUKES is false. Where does this leave us? Without an argument for REASONS GUIDE, and so without a reason to accept FILTER, and so without a guidancerelated objection to TRUTH or dilemmism. Conceptualising guidance in terms of reasons rather than norms and requirements doesn't help those who would level the guidance objection against dilemmism. ${ }^{51}$

Of course, the focus here has only been on a factualist implementation of the reasons-first programme. Not all adherents to the programme accept factualism. Some go in for propositionalism or psychologism. ${ }^{52}$ Could one of these approaches appeal to guidance considerations to rule out a view dilemmism in favour of a RATIONALITY-centric view? I am sceptical-I suspect that they will be unable to account for the irrationality of biased beliefs. However, there isn't space to discuss the issue here, so instead I will leave the ball in their court. If a workable argument can be constructed, it is up to them to construct it.

\section{Generalising}

We've looked at a number of ways of filling in the details of the guidance objection. On none of them does it tell against dilemmism. We have not looked at every way of filling in the details. Nevertheless, I suggest that the conclusion to draw from the

\footnotetext{
49 As several epistemologists have recently pointed out. See McHugh (2018), Littlejohn (2018), and Lasonen-Aarnio (2019).

${ }^{50}$ Lord's (2018) response to this objection is to appeal to the concept of 'relative weights'. I am not persuaded by it, but I cannot pursue the matter further here.

51 Even if we reject REASONS GUIDE, we might accept FILTER and REASONS-DETERMINE-OUGHTS on other grounds. Will the resulting epistemology do better than dilemmism when it comes to degrees of guidance? I think not. I suspect it will be unable to avoid the problems discussed in Sect. 7.

52 See Schroeder (2008) for propositionalism and Mantel (2018) for psychologism.
} 
foregoing is that there is no good objection to dilemmism to be found from guidance considerations.

But dilemmism was only a test case. Earlier I said that my goal was to show that guidance considerations have little role to play in helping us to decide between competing views about the fundamental norms of belief in general. If guidance considerations can't rule out dilemmism, what else can't they do?

\subsection{The nature of the fundamental norms}

Clearly, they cannot rule out unabashedly externalist views like process reliabilism and the knowledge norm of belief. Equally clearly, they cannot rule out externalist versions of RATIONALITY-centric views (neither, of course, can they undermine internalist RATIONALITY-centric views).

Nor will they help us to adjudicate between competing ways of thinking about rationality, such as evidentialism, normal-worlds reliabilism, 'normic support' views, mentalism, and dispositionalism. ${ }^{53}$ If it is a desideratum on a theory of epistemic rationality that it marks bias-infected beliefs as irrational, then, depending on how we conceptualise guidance, guidance failures will either be ubiquitous whichever way we go with the theory of epistemic rationality, or every theory will easily be capable of giving guidance.

Another result is that they cannot be used to choose between normative epistemologies according to which how one ought to conduct one's doxastic life is constrained by limitations on how one is able to conduct it, and epistemologies that do not posit this constraint. This follows from the fact that they cannot be used to motivate epistemic 'ought-implies-can' principles.

Yet another result is that they cannot be used to motivate thinking of some epistemic norms evaluatively, rather than deontically, as aims, goals, or ideals, rather than requirements. Those who are happy to endorse the idea that truth is an aim of belief (most epistemologists), but recoil at the idea that we are epistemically required to believe only truths (again, most epistemologists) will not find any support for their view from guidance considerations.

Generalising, it is difficult to use guidance-giving as a criterion by which to choose between competing approaches to the fundamental norms of belief.

So much for the fundamental norms. The point also generalises to other areas of normative epistemology. Which ones? A comprehensive answer to this question is beyond the scope of this paper. Nevertheless, here is a sample.

\subsection{Evidence and coherence}

Starting with our dilemmic theme, recently Christensen (2010a, 2010b, 2016), Worsnip (2018, fc), and I (Hughes, 2019b, fc1, fc2) have floated the idea that

\footnotetext{
53 For evidentialism, see Conee and Feldman (2004); normal-worlds reliabilism: Goldman (1986); normic support: Smith (2016); mentalism: Conee and Feldman (2004) and Wedgwood (2002, 2017); dispositionalism: Lasonen-Aarnio (2010, fc.). What about access internalism? If the argument of Sect. 7 is correct, it is not a tenable position.
} 
conflicts between substantive and structural norms of epistemic rationality should be thought of as dilemmas. One might have thought we should reject this idea on the grounds that the resulting epistemology would not be adequately guiding. But this would be a mistake. Instances of substantive rationality failing to give guidance are so commonplace anyway that there is nothing to be gained from cleaving to a nondilemmic normative epistemology on guidance grounds.

\subsection{Uniqueness and permissivism}

There are also implications for the uniqueness versus permissivism debate. Proponents of uniqueness maintain that for any given body of evidence, there is a unique rational doxastic attitude to take towards a proposition p given that evidence. Permissivists disagree. They maintain that sometimes more than one attitude is rationally permissible on a single body of evidence. ${ }^{54}$ A common argument against uniqueness and in favour of permissivism is that uniqueness is too demanding. ${ }^{55}$ If uniqueness was true, it would often be difficult to know what one is rationally required to believe. As a result, it would be difficult to conform with the demands of rationality. Why should this be an objection to the view? One obvious answer is that in virtue of making such exacting demands, epistemologies that endorse uniqueness fail to give us usable guidance. ${ }^{56}$ But the foregoing arguments show that this cannot ground the demandingness objection. A plausible permissivist epistemology must accept that unconsciously biased beliefs and credences are irrational. One consequence of this is that we will frequently fail to have the beliefs and credences that rationality requires, without having the ability to correct the problem, due to ignorance and an inability to control for such biases. Guidance failures will be ubiquitous even for the permissivist. As a result, it is highly doubtful that permissivists are in a better position than proponents of uniqueness when it comes to degrees-of-guidance.

Permissivists might reply that theirs is a non-ideal epistemology: uniqueness may well be right for agents with god-like cognitive abilities-permissivism is for us, with all our cognitive imperfections and limitations. But this reply misses the mark-biased beliefs are irrational, even for non-ideal agents like us.

\subsection{Bayesian epistemology}

The same dialectic plays out when it comes to Bayesian epistemology. Bayesianism requires one's credences to be probabilistically coherent. A common complaint is that this is unrealistically demanding. ${ }^{57}$ Amongst other things, it requires one to assign credence 1 to all logical truths and credence 0 to all logical falsehoods. A natural thought is that in virtue of making unrealistic demands, Bayesianism fails to

\footnotetext{
54 See Kopec and Titelbaum (2016) for an overview of this debate.

55 E.g. Schoenfield (2014)

56 Of course, this is not the only possible answer.

57 C.f. Titelbaum (ms).
} 
give usable guidance. But this observation cannot ground the demandingness objection for the same reason that it cannot ground an argument against uniqueness. And as before, it is not open to anti-Bayesians to argue that they are offering a nonideal epistemology.

\subsection{Sharp and mushy credences}

The dialectic also plays out in the debate about sharp versus mushy credences. Some epistemologists argue that our credences should sometimes be mushy-they should be spread out over intervals of real numbers (e.g. [0.3-0.5]), rather than precise real numbers (e.g. $0.41111 \ldots){ }^{58}$ One possible argument for mushy credences is the thought that an epistemology that requires sharp credences makes unrealistic demands. Guidance considerations cannot ground this argument, for the same reason as before.

\subsection{What's going on?}

These conclusions might seem surprising. It is patently obvious that only highly idealised counterparts to ourselves could possibly live up to the standards set by Bayesianism, uniqueness, and sharpness. Shouldn't this be taken into account when we construct our normative epistemology? No doubt it should. But the question is: on what grounds? I maintain that it cannot be on guidance grounds. Even when it comes to norms that don't look obviously demanding, we are in a much worse position, guidance-wise, than many epistemologists have (often tacitly) assumed. Once this fact is appreciated, the gap between norms that appear to be relatively undemanding and those that are obviously highly demanding shrinks dramatically.

Why has this point been overlooked? Part of the explanation may have to do with the kinds of cases that epistemologists working on what I have called the fundamental norms' usually focus on. The typical vignette in this area of epistemology involves a person receiving a new piece of information, usually through testimony or visual perception, contemplating it, and forming a new belief or revising an existing belief as a consequence, often about an object in their immediate vicinity. The way these vignettes are presented encourages us to think of this as a somewhat extended and effortful process that takes place at the forefront of the person's conscious mind. Moreover, they are designed to elicit a clear judgement about what rationality requires of the person. There is nothing wrong with the use of cases like these, of course, but they do tend to encourage a picture of our epistemic lives that is less rich, complex, and challenging than the reality (most of our beliefs are not about the colours of tables!) This focus may lead us to tacitly assume a more optimistic outlook on the prospects of being guided by a norm like RATIONALITY than is actually justified.

58 For an introduction to the debate, see Bradley (2019). 


\section{Conclusion}

I will close with some more positive remarks. Firstly, nothing I have argued here shows that guidance considerations should not play an important role in epistemologies which focus on local norms rather than very general norms like TRUTH and RATIONALITY. Secondly, consider TRUTH and RATIONALITY expressed in the conditional form 'You ought: if in circumstances $C$, then $\varphi$ '. A large part of the problem is that we are often not in a position to know whether the antecedents of the conditionals obtain. But this does not prevent us from knowing that the conditionals themselves are true. This knowledge can (and already does) serve as a useful guide in all kinds of ways. For instance, knowing that TRUTH and RATIONALITY are norms of belief, we should be motivated to avoid unreliable sources of evidence (compare Sect. 10.2). This is one of many ways of being guided by the most fundamental, general, epistemic norms that is easily available to everyone. But it is doubtful that this way of thinking about guidance can help us in theorising by narrowing down the range of acceptable fundamental norms. None of the views we have looked at is ruled out by it.

Acknowledgements For helpful discussion, thanks to Jonathan Way, Rachel Fraser, Bernhard Salow, Maria Lasonen-Aarnio, Kevin Dorst, Dominic Alford-Duguid, Tim Williamson, Jim Pryor, Claire Field, Clayton Littlejohn, two anonymous referees for Philosophical Studies, and audiences at New York University and the Universities of Vienna, Oslo, Oxford, and Cologne.

Open Access This article is licensed under a Creative Commons Attribution 4.0 International License, which permits use, sharing, adaptation, distribution and reproduction in any medium or format, as long as you give appropriate credit to the original author(s) and the source, provide a link to the Creative Commons licence, and indicate if changes were made. The images or other third party material in this article are included in the article's Creative Commons licence, unless indicated otherwise in a credit line to the material. If material is not included in the article's Creative Commons licence and your intended use is not permitted by statutory regulation or exceeds the permitted use, you will need to obtain permission directly from the copyright holder. To view a copy of this licence, visit http:// creativecommons.org/licenses/by/4.0/.

\section{References}

Alverez, M. (2010). Kinds of reasons. Oxford University Press.

Audi, R. (1994). Dispositional beliefs and dispositions to believe. Nous, 28(4), 419-434.

Austin, J. L. (1957). A plea for excuses. Proceedings of the Aristotelian Society, 57, 1-30.

Barnett, D. manuscript. Testimony internalism, stored beliefs, and forgotten evidence.

Blanshard, B. (1974). Reason and belief. Allen and Unwin.

Boghossian, P. (2003). The normativity of content. Philosophical Issues, 13, 31-45.

Boghossian, P. (2008). Epistemic rules. Journal of Philosophy, 105(9), 472-500.

Bradley, S. (2019). Imprecise probabilities. In Zalta, E. (Ed.), The Stanford encyclopaedia of philosophy.

Brownstein, M. (2019). Implicit bias. In Zalta, E. (Ed.), The Stanford encyclopaedia of philosophy.

Christensen, D. (2010a). Higher-order evidence. Philosophy and Phenomenological Research, 81, $185-215$.

Christensen, D. (2010b). Rational reflection. Philosophical Perspectives, 24, 121-140.

Christensen, D. (2016). Conciliationism, uniqueness, and rational toxicity. Nous, 50, 584-603. 
Cohen, S., \& Comesana, J. (forthcoming). Rationality and truth. In Dutant, J., \& Dorsch, F. (Eds.), The new evil demon problem. Oxford University Press

Comesana, J., \& McGrath, M. (2014). Having false reasons. In C. Littlejohn \& J. Turri (Eds.), Epistemic norms. Oxford: Oxford University Press.

Conee, E., \& Feldman, R. (2004). Evidentialism: Essays in epistemology. Oxford University Press.

Davidson, D. (1963). Actions, reasons, and causes. Journal of Philosophy, 60, 685-699.

Engel, P. (2013). In defence of normativism about the aim of belief. In T. Chan (Ed.), The aim of belief.Oxford University Press.

Fassio, D. \& Gao, J. (forthcoming). Do we really need a knowledge-based decision theory. Synthese.

Feldman, R. (2000). The ethics of belief. Philosophy and Phenomenological Research, 60(3), 667-695.

Fox, P. (2019). Revisiting the argument from action-guidance. Journal of Ethics and Social Philosophy, 15(3), 222-254.

Gibbons, J. (2013). The norm of belief. Oxford University Press.

Ginet, C. (1975). Knowledge. Reidel.

Gluer, K., \& Wikforss, A. (2009). Against content normativity. Mind, 118(469), 31-70.

Gluer, K., \& Wikforss, A. (2010). The truth norm and guidance: A reply to Steglich-Petersen. Mind, 119, 757-761.

Gluer, K., \& Wikforss, A. (2013). Against belief normativity. In T. Chan (Ed.), The aim of belief. Oxford University Press.

Goldman, A. (1986). Epistemology and cognition. Harvard University Press.

Goldman, A. (1999). Internalism exposed. Journal of Philosophy, 96(6), 271-293.

Greco, D. (2012). The impossibility of skepticism. The Philosophical Review, 121(3), 317-358.

Greco, D. forthcoming. On the very idea of an epistemic dilemma. In Hughes, N. (Ed.), Essays on epistemic dilemmas. Oxford University Press.

Huemer, M. (2001). Skepticism and the veil of perception. Rowman \& Littlefield.

Hughes, N. (2014). Is knowledge the ability to $\varphi$ for the reason that P? Episteme, 4(11), 457-462.

Hughes, N. (2017). No excuses: Against the knowledge norm of belief. Thought: A Journal of Philosophy, 6(3), 157-166.

Hughes, N. (2018a). Luminosity failure, normative guidance, and the principle ought-implies-can. Utilitas, 30(4), 439-457.

Hughes, N. (2018b). Guidance, obligations, and ability: A close look at the action guidance argument for ought-implies-can. Utilitas, 30(1), 73-85.

Hughes, N. (2019a). Dilemmic epistemology. Synthese, 196, 4059-4090.

Hughes, N. (2019b). Uniqueness, rationality, and the norm of belief. Erkenntnis, 84, 57-75.

Hughes, N. (forthcoming-1). Epistemic dilemmas defended. In Hughes, N. (Ed.), Essays on epistemic dilemmas. Oxford University Press.

Hughes, N. (forthcoming-2). Who's afraid of epistemic dilemmas?. In McCain, K., Stapleford, S., \& Steup, M. (Eds.), Epistemic dilemmas: New arguments, new angles. Routledge.

Hughes, N. (forthcoming-3). Evidence and bias. In Lasonen-Aarnio, M., \& Littlejohn, C. (Eds.), The Routledge handbook of the philosophy of evidence. Routledge.

Hughes, N. (manuscript). Epistemic feedback loops (or: how not to get evidence).

Hyman, J. (1999). How knowledge works. Philosophical Quarterly, 49(197), 433-451.

Hyman, J. (2015). Action, knowledge, and will. Oxford University Press.

Jay, C. (2012). Impossible obligations are not necessarily deliberatively pointless. Proceedings of the Aristotelian Society, 113, 381-389.

Kiesewetter, B. (2017). The normativity of rationality. Oxford University Press.

Kopec, M., \& Titelbaum, M. (2016). The uniqueness thesis. Philosophy Compass, 11(4), 189-200.

Langsam, H. (2008). Rationality, justification, and the internalism/externalism debate. Erkenntnis, 68(1), 79-101.

Lasonen-Aarnio, M. (2010). Unreasonable knowledge. Philosophical Perspectives, 24, 1-21.

Lasonen-Aarnio, M. (2019). Guidance, epistemic filters, and non-accidental ought-doing. Philosophical Issues, 29(1), 172-183.

Lasonen-Aarnio, M. (forthcoming). Virtuous failure and victims of deceit. In Dutant, J., \& Dorsch, F. (Eds.), The new evil demon problem. Oxford University Press.

Littlejohn, C. (2013). The Russellian retreat. Proceedings of the Aristotelian Society, 113(3), $293-320$. 
Littlejohn, C. (forthcoming). A plea for epistemic excuses. In Dutant, J., \& Dorsch, F. (Eds.), The new evil demon problem. Oxford University Press.

Littlejohn, C. (2018). Being more realistic about reasons: On rationality and reasons perspectivism. Philosophy and Phenomenological Research, 99(3), 605-627.

Lord, E. (2015). Acting for the right reasons, abilities, and obligation. In R. Shafer-Landau (Ed.), Oxford studies in metaethics. (Vol. 10). Oxford University Press.

Lord, E. (2018). The importance of being rational. Oxford University Press.

Lord, C. G., Ross, L., \& Lepper, M. R. (1979). Biased assimilation and attitude polarization: The effects of prior theories on subsequently considered evidence. Journal of Personality and Social Psychology, 37(11), 2098-2109.

Mantel, S. (2018). Determined by reasons: A competence account of acting for a normative reason. London: Routledge.

McHugh, C. (2018). Review of the normativity of rationality by Benjamin Kiesewetter. Mind, 127(508), $1245-1253$

Mele, A. (2002). Agents' abilities. Nous, 37, 447-470.

Nelson, M. (2010). We have no positive epistemic duties. Mind, 119(473), 83-102.

Neta, R. (manuscript). Access internalism and the guidance-deontological conception of justification.

Pollock, J. (1987). Epistemic norms. Synthese, 71, 61-95.

Railton, P. (2006). Normative guidance. In R. Shafer-Landau (Ed.), Oxford studies in metaethics (Vol. 1, pp. 3-34). Oxford University Press.

Rinard, S. (2018). Reasoning one's way out of skepticism. In K. McCain \& T. Poston (Eds.), The mystery of skepticism. Brill.

Roese, N., \& Vohs, K. (2012). Hindsight bias. Perspectives on Psychological Science, 7(5), 411-426.

Schoenfield, M. (2014). Permission to believe: Why permissivism is true and what it tells us about irrelevant influences on belief. Nous, 48(2), 193-218.

Schroeder, M. (2008). Having reasons. Philosophical Studies, 139, 57-71.

Siegel, S. (2017). The rationality of perception. Oxford University Press.

Smith, H. (2012). Using moral principles to guide decisions. Philosophical Issues, 22, 369-386.

Smith, M. (2016). Between probability and certainty. Oxford University Press.

Smithies, D. (2019). The epistemic role of consciousness. Oxford University Press.

Srinivasan, A. (2015). Normativity without cartesian privilege. Philosophical Issues, 25(1), 273-299.

Steglich-Petersen, A. (2013). The no guidance argument. Theoria, 79, 279-283.

Sullivan-Bissett, E. (2018). Explaining doxastic transparency: Aim, norm, or function? Synthese, 195, 3453-3486.

Sutton, J. (2005). Stick to what you know. Nous, 39(3), 359-396.

Sutton, J. (2007). Without justification. MIT Press.

Talbot, B. (2016). The best argument for 'ought implies can' is a better argument against 'ought implies can. Ergo, 3(14), 377-402.

Titelbaum, M. (manuscript). Fundamentals of Bayesian epistemology.

Treanor, N. (2013). The measure of knowledge. Nous, 47(3), 577-601.

Way, J. (2016). Two arguments for evidentialism. The Philosophical Quarterly, 66(265), 805-818.

Way, J., \& Whiting, D. (2016). Reasons and guidance (or: surprise parties and ice cream). Analytic Philosophy, 57(3), 214-235.

Wedgwood, R. (2002). Internalism explained. Philosophy and Phenomenological Research, 65(2), 349-369.

Wedgwood, R. (2017). The value of rationality. Oxford University Press.

Williamson, T. (2000). Knowledge and its limits. Oxford University Press.

Williamson, T. (2013). Response to Cohen, Comesana, Goodman, Nagel, and Weatherson on Gettier cases in epistemic logic. Inquiry an Interdisciplinary Journal of Philosophy, 56(1), 77-96.

Williamson, T. (2014). Very improbable knowing. Erkenntnis, 79, 971-999.

Williamson, T. (forthcoming). Justifications, excuses, and sceptical scenarios. In Dutant, J., \& Dorsch, F. (Eds.), The new evil demon problem. Oxford University Press

Wilson, T. (2002). Strangers to ourselves. Harvard University Press.

Wilson, T., \& Brekke, N. (1994). Mental contamination and mental correction: Unwanted influences on judgments and evaluations. Psychological Bulletin, 116(1), 117-142. 
Worsnip, A. (2018). The conflict of evidence and coherence. Philosophy and Phenomenological Research, 96(1), 3-44.

Worsnip, A. (forthcoming). Evidence-coherence conflicts revisited. In Hughes, N. (Ed.), Essays on epistemic dilemmas. Oxford University Press.

Publisher's Note Springer Nature remains neutral with regard to jurisdictional claims in published maps and institutional affiliations. 